\title{
E-Business Performance Analysis: A Case Of A Slovenian e-Shop
}

Metka Tekavčič, (E-mail: metka.tekavcic@uni-lj.si), Faculty of Economics Ljubljana, Slovenia Mojca Marc, (E-mail: mojca.marc@uni-lj.si), Faculty of Economics Ljubljana, Slovenia

\begin{abstract}
This paper is part of our on-going work in the field of business performance analysis in eenvironment. We put forward a framework that tries to link different aspects of performance analysis and to relate them to broader business environment on the one hand, and to the value of a company on the other. We illustrate the use of the proposed framework with a case study examining the Slovenian home-store company Merkur, which operates one of the best Slovenian on-line shops. The framework can also serve as a tool for an empirical analysis.
\end{abstract}

\subsection{Introduction}

$E$

-business is becoming an important part of business processes in the global economy. Although it looked as if the new born "dot-coms" would dominate the new economy, it is now becoming obvious that many traditional companies successfully implemented e-business strategies and processes. Business performance analysis had to adapt to this development. In our previous work (Tekavčič, Marc, 2003), we showed that ebusiness performance analysis focuses primarily on five fields of work: customers (visitor acquisition, conversion and customer retention), operational excellence (velocity, quality and efficiency of inbound logistics, operations, sales, delivery and service), human capital (growth/renewal, efficiency, stability), intangibles (intangibles, intellectual capital value) and finance (revenue growth and structure, costs reduction, assets usage efficiency, liquidity). We also researched various new measures that are currently used for evaluating and monitoring these fields of analysis and were developed specifically or largely for e-business companies.

The relevant literature on business performance analysis is very fragmented. Particular parts of performance analysis usually have a very narrow coverage. In this paper we therefore attempt to link the different areas of e-business performance analysis and to form a comprehensive framework for analyzing e-business companies. We describe the presumed relationships and links between different parts of the framework and between different fields of performance analysis, together with some measures that can be used for analyzing the latter.

In the second part of the paper we illustrate the use of the developed framework with a case study, where we examine the Slovenian home-store company Merkur, which operates one of the best Slovenian on-line shops. Merkur's on-line shop http://nakup.merkur.si has been operating since November 2000. Like many other ebusinesses, it is not yet profitable. It was born as a marketing project whose missions were 1) to enhance company's image, 2) to influence buying decisions, and 3) to sell. It is above all intended for promotion, acquiring e-business know-how and experience. Profitability is thus somewhat less important at the moment.

We conclude the paper with some final remarks and provide several suggestions for future research.

Readers with comments or questions are encouraged to contact the authors via email. 


\subsection{A General Framework For Analyzing E-Business Performance}

The idea of a general model for analyzing business performance is to show causality among different factors that affect business performance. The framework that is illustrated in Figure 1 gives a graphical representation of the key parts of performance analysis that were discussed in our previous work (Marc, Tekavčič, 2003). We included also some examples of measures/indicators that can be used to evaluate various parts of analysis, but it is understandable that every company needs to adapt these in a manner that corresponds to their business, strategies and goals. We focused primarily on new measures that are more specific for e-business than for traditional companies. As e-business models differ, we cannot uniformly prescribe measures to be used for performance analysis.

With this framework we attempt to provide a comprehensive overview of business performance analysis in e-environment including company valuation and broader business environment. Other similar models, like Balanced e-Scorecard (Melymuka, 2001), Performance Prism (Adams et al., 2000 - 2001), e-Metrics Compass (Donath, 1999), Internet Value Matrix (Cisco Corporation, 2001) or Digital Value Added (Stern Stewart \& Co., Razorfish Inc., 2001), do not deal with this explicitly. The outline of the model resembles a house, so we named the component parts "the roof", "the bricks" and "the foundation". In the following section we explain the elements of the framework and some assumed links among them.

\subsection{The "Roof"}

Financial theory states that maximizing shareholders' value i.e. the value of a company, is the optimal goal of a company. Therefore value sits on the top of the framework, as the result of all factors that can influence it. Emerging e-business companies instigated some new methods for valuating business. For example, in addition to commonly used traditional methods (discounted cash flows and multiples), Sawhney (2001) lists four new methods: multiples analysis, net metrics, qualitative factors and backward discounted cash flows. These methods are in fact largely variations of traditional methods. They were developed mainly because the majority of companies concerned had no profit, which is one of the inputs in traditional valuating methods. Instead, other measures were introduced as profit and cash flow indicators. Adjustments of traditional methods were hence necessary. Sawhney (20001) further recommends real option pricing methods, especially for valuing Internet companies. These companies are typically in the starting phase of their life cycle and thus face great uncertainty, which can be treated as a portfolio of real options.

\subsection{The "Bricks"}

The core of the framework consists of nine "bricks", representing different parts of business performance analysis. They are arranged according to their presumed influence on each other and on the value of a company.

\subsubsection{The First Row}

Elements in the top row of "bricks" are the ones that have the strongest and immediate influence on the value of a company. While financial performance and required net investment in operating capital directly affect free cash flow, intellectual capital increases the value of a company also through many real options that a company can benefit from. The link between financial performance and value is quite straightforward. It has been mentioned that there is the need to evaluate financial performance with some sort of profit indicators (sales, costs, users etc.) instead of profit itself. The required net investment in operating capital is included in the framework foremost because it affects free cash flow, which is one of the inputs in valuating methods. Besides, Mauboussin and Hiller (1999) found out that some Internet companies have negative required investment in working capital, which in fact represent cash inflows. On the basis of this, authors concluded a part of value of Internet companies could come from this direction. Many authors agree that intellectual capital has an important influence on a company's value (Sawhney, 2001, McLean, 1995, Upton, 2001), partly through greater profit and/or cash flow, partly through various strategic, real options. 
Figure 1: A Framework for Analyzing Business Performance in e-Environment

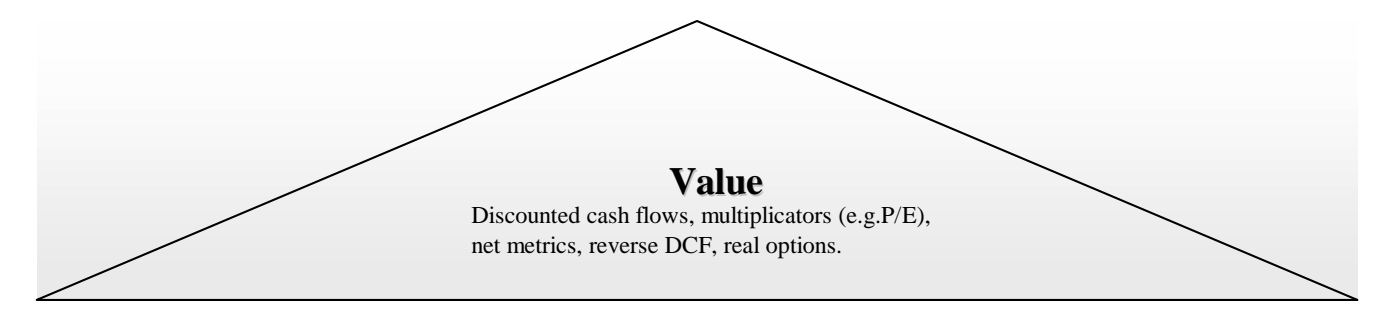

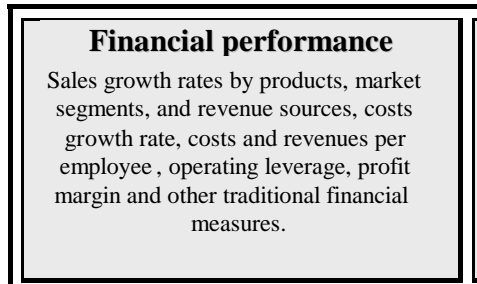

\begin{tabular}{|c|}
\hline Conversion and \\
customer retention \\
Customer acquisition cost, customer \\
conversion rate, revenue per transaction \\
and per customer, number of repeat - \\
customers, acquisition cost and revenue \\
per repeat customer etc. \\
\hline
\end{tabular}

\begin{tabular}{|c|}
\hline Visitor acquisition \\
Total site reach, number of visitors, \\
acquisition costs per visitor, frequency \\
(number of visits per visitor) and duration \\
(average duration of visit), stickiness, \\
freshness factor etc. \\
\end{tabular}

\section{Business model}

Type of business model, market orientation (B2C, B2B, C2C),

revenue sources, pricing, value offer, market size and other measures of industry competitiveness.

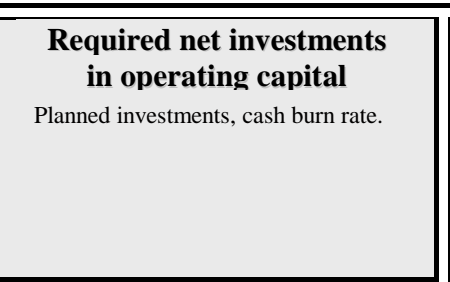

Asset usage efficiency

Investments to sales ratio, R\&D expenditures to sales, cost of developing brand names to sales, traditional (financial) measures of asset usage efficiency etc.

\section{Operational excellence}

Total duration of the processes, time to complete customer's order, time to load a web page, logicality of website structure, the percentage of improperly fulfilled orders etc.

\section{Intellectual capital}

Number of patents, invest ments in ICT, investments in $\mathrm{R} \& \mathrm{D}$, brand awareness indices, market -to-book ratio, Tobin's q ratio, Strassmann's knowledge capital value, calculated intangible value etc.

\section{$\|$}

\section{Knowledge base}

Number of years in the profession, education level, training and education costs, marking, competence turnover, competence -enhancing customers, number of completed projects, number of inte rnal workshops and seminars etc.

\section{Employee productivity} and satisfaction

Professionals turnover, relati ve pay, seniority, employee satisfaction index, value added per employee revenues and costs per employee visitors/ users/ customers per employee, website's stickiness etc.

\section{Organisation} Internal: organisational structure, number of hierarchical levels. External: number of partner companies, position in the value chain or value network

E-environment (economy and society)
PC and Internet penetration, number of ISPs, number of websites, internet hosts and secure servers,
PCs and Internet connections in schools, percentage of e -shoppers in the internet users population,
percentage of e-commerce or e -business companies in the economy etc.

\subsubsection{The Second Row}

In the center row of the "bricks" there are elements that have an obvious effect on elements in the first row, including: conversion and customer retention, asset usage efficiency and knowledge base. Conversion and customer retention influence sales, which is one of the key determinants of financial performance. It is precisely this part that is especially critical for e-business's success, as companies have not yet found the "miracle formula" for converting numerous visitors into customers and retaining existing customers. Technology made evaluating and monitoring of this field of analysis much easier and more thorough than in the case of traditional companies. Asset usage efficiency has influenced required net investment in operating capital, as well as costs, which are a determinant of financial performance. This part of analysis is also important for traditional companies, but we can point out some measures that are more suitable for companies in the beginning stages of their life-cycle. First, traditional measures, 
e.g. asset turnover, use accounting assets, which do not include all "assets" that these companies operate with (the problem of intangibles). Secondly, some measures use profit, which is generally not made in this phase of the lifecycle. Maintaining and building knowledge base makes increasing of intellectual capital possible. At the same time it can influence operational excellence, productivity and employee satisfaction.

\subsubsection{The Third Row}

Elements in the last row of the "bricks" represent business fundamentals and act primarily on elements in the center row. They are visitor acquisition, operational excellence and employee productivity and satisfaction. Visitor acquisition is a field of analysis that can be evaluated and monitored more thoroughly for e-business than for traditional companies, therefore many new measures have already developed. Research by Lev and Demers (2000 showed that some of these new measures (e.g. website's stickiness) do not influence only customer conversion, but were considered also by investors. From this we could infer that this part of performance analysis has also a direct influence on a company's value. On the other hand, it is also probable that these new measures were considered simply as a substitute for other (financial) performance measures. Operational excellence is important for every company. It affects all elements in the center row, as well as visitor acquisition. The velocity and quality of processes influence visitor and customer acquisition, while its efficiency has an effect on asset usage efficiency. Some processes have become completely or partially electronic. New measures for this field of analysis have evolved primarily where the technology is new; otherwise traditional or somewhat adapted measures are used. Employee productivity and satisfaction are the sources of successful business performance. They are linked foremost to operational excellence and knowledge base, as well as to other elements in the framework. Because there are relatively few experienced professionals, employees represent a valuable resource for e-business companies. This part of the performance analysis is therefore very critical for them; unfortunately there are only a few measures for evaluating and monitoring this element of analysis.

\subsection{The "Foundation"}

When evaluating business performance of companies operating in e-environment, it is necessary to consider a wider set of elements as in the case of traditional companies. For example, the latter have familiar, standard, tried and tested business models and they operate in a relatively stable, predictable and well-known environment. In contrast to this, e-business companies try business models that emerged only recently. Before analyzing a concrete e-business company, potentials and risks of its business model should be evaluated too, especially if it is a novelty. A business model can be analyzed in view of the characteristics of the "sub-models", or components, as described by Nunes (2000). These can be e.g. pricing model, revenue model, channel model etc. A business model determines to a certain extent the size and the characteristics of the visitors' or customers' base, the structure and velocity of operational processes and also the organization (internal and/or external) of the company.

The company's organization (internal and/or external) influences the characteristics of operational processes in a similar way as business models (it goes in the other way too). Besides, it can affect the productivity and employees' satisfaction. A business model or an organization can directly increase the value of a company, for example, if a business model allows the first mover advantage or if a company takes part in a developed value network.

A business model and organization have to be evaluated with regard to the general e-environment (economy and society), as this predetermines the rationale and potential for a business model or organization.

\subsection{On-Line Shop Merkur}

Merkur is the biggest home-store company operating mainly in Slovenia. Its on-line shop ${ }^{1}$ received Netko award for the best website and on-line shop in Slovenia in 2002 and this is why we chose it as our example. It set up

\footnotetext{
${ }^{1}$ See URL: [http://nakup.merkur.si]
} 
its on-line shop already in November 2000; in May 2001 it was renovated to its present form. It was born as a marketing project, whose missions were: 1) to enhance corporate image, 2) to influence buying decisions, and 3) to sell. It is intended above all for promotion, acquiring e-business know-how and experience, profitability is somewhat less important at the moment.

The on-line shop also does not represent a profit or a cost center for Merkur. This represented a major obstacle for the analysis as all costs had to be estimated. Furthermore, only two people work on this project in the company, one is from the marketing department (Internet communication editor), while the other manages on-line orders. They cooperate with two outside companies: one designs their web pages and the other publishes the electronic catalogue on the Internet. Also, they do not have any system for monitoring business performance of the on-line shop. Because of this, we decided to analyze only some parts of the framework: e-environment, business model, visitor acquisition, operational excellence and customer conversion and retention. We analyzed visitors' activity and customer conversion and retention in the period from January 2001 to June 2002, covering 18 months. All data has been transformed in order to keep them confidential. Relations between numbers have been preserved. The analysis is based on real, i.e. inflation adjusted, data. We used monthly data wherever possible; otherwise employees' estimations were used.

\subsection{E-environment}

In this section, we present the results of the research project RIS (Raba Interneta v Sloveniji - Internet Usage in Slovenia) $)^{2}$, which has been carried out every year since 1996.

\subsubsection{E-economy}

The RIS project results (December 2000/January 2001) ${ }^{3}$ show that practically all big companies and the majority of smaller ones use the Internet, mainly to gather business information and communicate, but rarely to carry out business processes. Only $10 \%$ of companies that have Internet access generate e-business revenues, which typically represent less than $1 \%$ of total revenues, but the majority of companies believe that the Internet has important influence on their business. Electronic banking transactions are widely used, while on-line sale and electronic ordering (e-procurement) are limited to a few percent of all companies or orders, respectively.

A half of companies with Internet access use e-business (i.e. document exchange with up to 5 partners). The reasons for its implementation are better service quality, flexibility, competitive advantage and new markets, followed by somewhat less important cost reduction and sale increase. Most companies consider that e-business implementation should reduce costs by more than $10 \%$ to be justified. Besides, companies listed human and financial resources shortage as the main obstacles to greater implementation. Companies using e-business think that it will be the prevalent standard of doing business for their industry in the period of 2-3 years.

\subsubsection{E-society}

In its beginning, the spread of Internet usage in Slovenia was one of the fastest in Europe, due to the availability of new technologies, politics of $\mathrm{Arnes}^{4}$ and relatively low priced telephone services (Vehovar, 2000). Early Internet absorption was typical primarily of male, urban, educated and computer-savvy users, with a good knowledge of English language and the rest of population somewhat lagging behind. However, after 1998 the growth in Internet usage, compared to European average, has slowed down: in 1998 the share of Internet users in Slovenian population (15 years and older) was at the European average level, whereas in July 2001 it was about half as big (25\% as opposed to 47\%). Nevertheless, the latest data show that in May 2003 there were about 642,000

\footnotetext{
${ }^{2}$ The RIS project is an academic and nonprofit research project at the University of Ljubljana, Faculty of Social Sciences. It is dedicated to gather, interconnect and analyze empirical data connected with the relevant aspects of the Internet. See URL: [http://www.ris.org].

${ }^{3}$ See URL: [http://www.ris.org/publikacije/j_eposlovnj.htm].

${ }^{4}$ Academic and Research Network of Slovenia, an institution whose main task is to develop, operate and manage the communication and information network for education and research.
} 
active users (about $32 \%$ of the population) and more than 900,000 persons (about $45 \%$ of the population) who have used the Internet at least once (RIS, 2003).

The major purpose of regular usage in Slovenia is business, personal (communication, hobbies etc.) and general information search. In the first half of 2001 about $12 \%$ of active users (i.e. 50,000 users) purchased items over the Internet over the last 12 months (RIS 2000/2001). Almost half of them shop exclusively at non-Slovenian websites. RIS researchers estimated that overall e-sales in 2001 amounted to near SIT 2 billion (about EUR 9 million). In general, e-shoppers are relatively satisfied with the state of e-commerce in Slovenia, but they find commercial e-mails following accomplished purchases especially disturbing. The main constraints for more extensive use of e-shopping are: delivery problems, the fact that one cannot touch the items for sale, distrust in paying process security and the like ${ }^{5}$.

\subsection{Business model}

Merkur's on-line shop is a typical B2C on-line shop, but in the future Merkur plans to upgrade it also for B2B operations. At the moment, sale is the only revenue source for the on-line shop. There are more than 2,000 items users can choose from, which are available in Merkur's physical stores as well. Prices are the same as in traditional stores, convenience of on-line shopping and 24-hours service are thus the main benefits for users. Some additional features like order status tracking, tips for home and garden, e-news, users' forum, e-cards, FAQs are also part of this website. Customers can pay on-line by credit cards or C.O.D. Delivery is free for orders exceeding SIT $10,000 \mathrm{SIT}^{6}$ and goods are usually delivered in two days. Delivery is carried out by post, except in cases of larger products when own transportation is used.

\subsection{Visitors' Activity}

In order to analyze visitors' activity we processed log files from server nakup.merkur.si with a test version of WebTrends, a software for analyzing web data. First we analyzed log files month by month and retrieved the number of unique visitors for each month (monthly visitors), average number of visits per unique visitor (frequency), and average length of visit (duration). Among monthly visitors there were some first time visitors (new visitors) and others, who had already visited the website in the past months. For the purpose of finding out the number of new visitors each month, we analyzed log files also collectively, i.e. we counted unique visitors that visited the website till the previous month included in the processing of data (visitors' base) ${ }^{7}$. The difference between two consequent visitors' bases gave us the number of new visitors in the last month included in the analysis.

Visitors' base increased more than seven times during the studied time period (see Figure 3). The number of unique visitors per month was on average increasing by $7 \%$. About $30 \%$ of them were new visitors, on average, but the share of new visitors was in general declining over time. Total monthly site reach was on average $46 \%$. This means that on average about $46 \%$ of visitors' base was active (visited at least once in a month). The increase in the visitors' base was the result of advertising, as a Merkur's study showed that the number of visits increased mostly after publishing promotional catalogues and sending advertising e-mail (Merkur, 2001)

Acquisition costs (mainly advertising) were about $47 \%$ higher in 2002 than the year before. Average acquisition cost per monthly visitor fell from SIT 28 in 2001 to SIT 17 in $2002^{8}$, which means that the increased advertising was cost efficient. We came to the same conclusion when comparing acquisition costs for new visitors.

\footnotetext{
${ }^{5}$ See URL: [http://www.ris.org/si/ris2000/novice/20010412.html].

${ }^{6}$ About $€ 43$.

${ }^{7}$ For example, we first analyzed log files for January, then for January and February together, next we used $\log$ files for January, February and March and so on. Each time the processing of data was performed, the data series was longer for one month.

${ }^{8}$ About $€ 0,12$ and $€ 0,07$, respectively.
} 
Figure 3: Visitors reach ${ }^{9}$

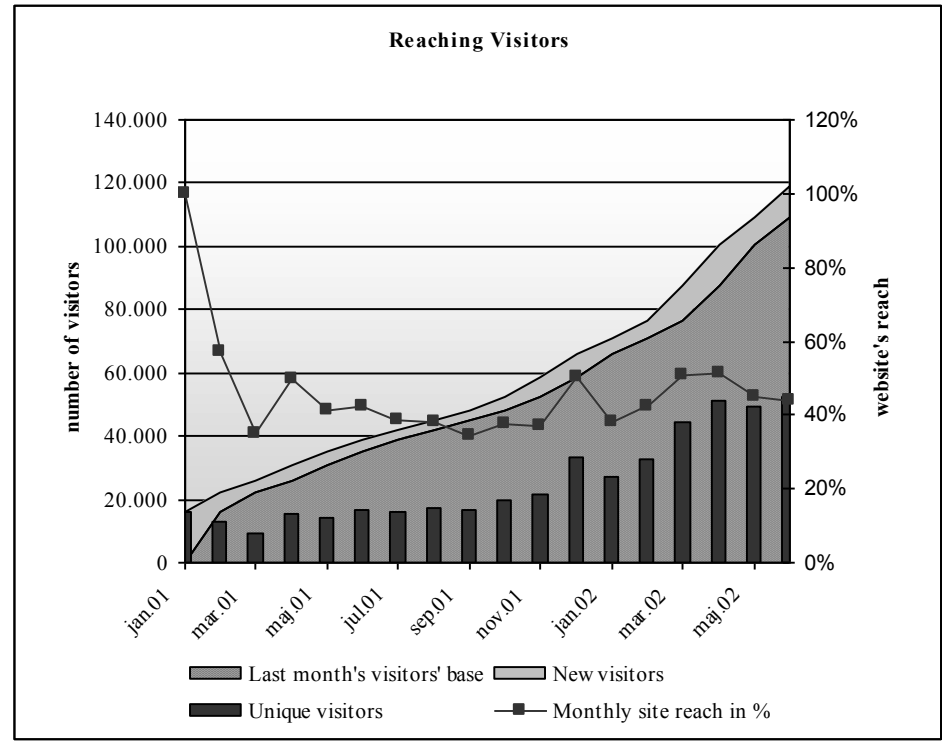

Source: Marc, 2003

Figure 4: Visitors' Activity

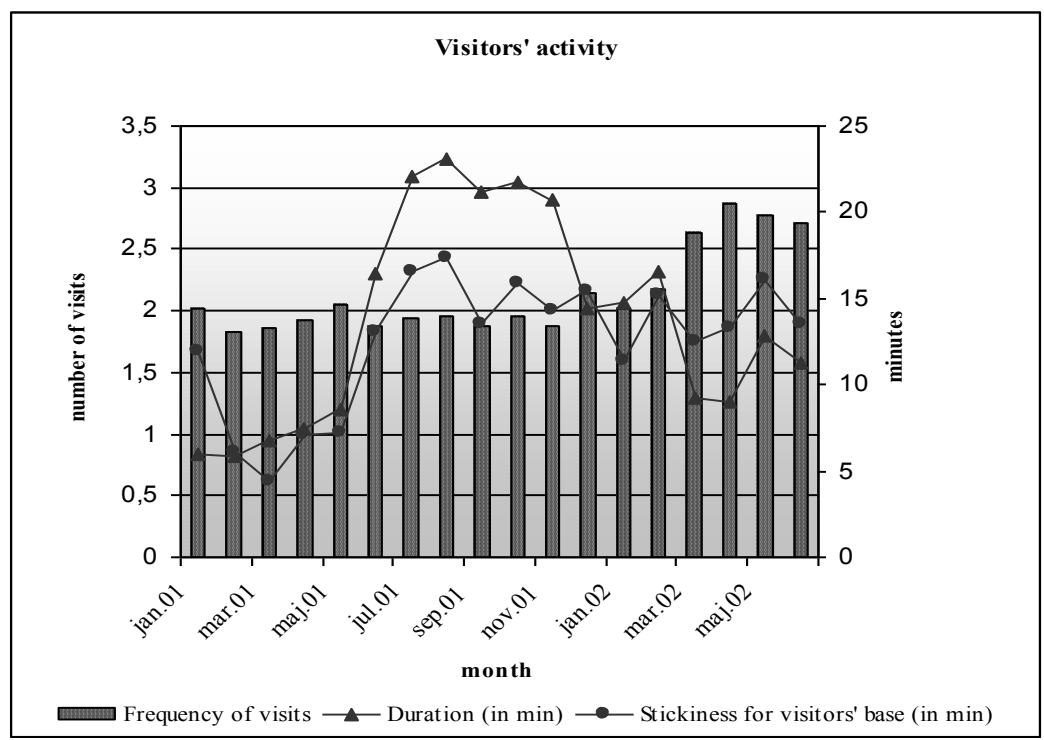

Source: Marc, 2003.

${ }^{9}$ Note: visitors numbers have been transformed to keep them confidential. 
The frequency of monthly visits was on average increasing, whereas their duration was on average decreasing: an average visitor made 1.9 visits per month and spent 14.5 minutes on the website in 2001 , while in the first half-year of 2002 he/she made 2.5 visits per month and spent 12 minutes on the website (see Figure 4). Website's stickiness was generally increasing. The renovation in May 2001 was successful, as shown by a high jump in stickiness numbers.

These data demonstrate that visitors find the website useful, because they keep coming back. Besides, they have already got used to the website as they visit it more frequently, but their visits are shorter. We can supply two reasons for this: 1) visitors find what they are looking for more quickly, and/or 2) visitors are already familiar with the content and they find it less interesting. The first reason can be supported by an analysis that was performed by Merkur showing that visitors mostly follow this click-path: they enter through home page, use the search engine or view some special offer, and exit after viewing individual products (Merkur, 2001). The second reason can be supported by a decreasing freshness factor (average refreshments of the content vs. average frequency of visits).

\subsection{Operational excellence}

We combined the many operating processes that take place in Merkur's on-line shop into three main ones: 1) preparing electronic catalogue and web pages (creating content), 2) processing on-line orders and 3) delivery and post-sale services. Presently Merkur does not follow systematically the performance of any of these processes, so each parameter had to be estimated. The performance of all processes can be analyzed in terms of their 1) velocity, 2) quality and 3) efficiency.

\subsubsection{Velocity}

We could get a sort of assessment for velocity only for the process of delivery. The employees estimate that usually the guaranteed two-day delivery term limit is met.

\subsubsection{Quality}

The quality of the process of preparing web pages can be estimated by their stickiness ${ }^{10}$. Stickiness improved greatly after the renewal of the on-line shop in May 2001, which shows that the renovation was successful, but on average it has been slowly falling ever since. One of the reasons for this could be, as mentioned above, a smaller freshness factor.

The quality of the on-line shop's content has to be assessed also in view of the number of items available, information about products, the logical structure and visual image of the website. A research by Merkur showed that users criticize mostly the small number of items available, but they are quite satisfied with the straightforward logical structure and its appealing graphic design. We should mention that the number of products available augmented almost three times in the period studied.

We could estimate the quality of processing orders and delivery only by counting the number of complaints made. In the first six months of operating, the number of cases was high, as they represented about $27 \%$ of orders. Since then, the quality has improved. In 2002 complaints were made only for 4 out of 100 orders.

\subsubsection{Efficiency}

We were able to assess cost efficiency only for the processes of creating content and delivery and by using employees' estimations. The costs of creating content dropped enormously in 2002, the reason being the one time impact of the extensive renovation in 2001. Not counting that, the costs in the first half of 2002 actually increased by $26 \%$ if compared to first half of 2001. Nevertheless, the average cost of creating content per visitor was lower by 42

\footnotetext{
${ }^{10}$ Measures the effectiveness of a website to hold visitors' attention.
} 
$\%$ in 2002 and this shows that the efficiency of the process improved. The average cost of delivery per order in 2002 was $3 \%$ lower than in the year before, which also shows better efficiency. It would be fairly easy to decrease costs, namely by canceling free delivery. Yet it is precisely free delivery that is presently one of the most important competitive advantages in B2C. It is very appreciated by customers, however only a few on-line shops can afford it.

\subsection{Customer Conversion And Retention}

We used Merkur's data on its on-line customers and MS Excel to analyze customer conversion and retention. We performed the customers' analysis first month by month (monthly customers) and then also collectively (customers' base), in the same way as with the visitors' data, in order to calculate new customers for each month. Because the company does not have the necessary data, we were not able to link individual customers with all their visits, analyze their click-path or measure shopping cart abandonment.

The number of monthly customers was on average increasing by $3 \%$ in the studied time period, while the customers' base increased about twenty times during this period. On average, about $80 \%$ of monthly customers were new. This may seem a lot, but the conversion rates show quite a different picture. The conversion from monthly visitors to monthly customers was overall decreasing. On average, only $1.2 \%$ of monthly visitors purchased a product and in June 2002 there was $3.2 \%$ customers in the visitors' base. A McKinsey study showed that average conversion rates did not reach $5 \%$, whereas best websites had conversion rates around $12 \%$ (Agrawal et al. 2001).

In order to measure customer retention and attrition, we had to define when a customer is considered retained or attrite. We decided that customers who made at least two purchases in the last six months, would be regarded as retained. Customers who did not make a single purchase in the last six months would be regarded as attrite. In the customers' base there were on average about $9 \%$ retained customers and about $39 \%$ attrite customers. A good half of customers made exactly one purchase in the last six months. On average, retained customers' purchases corresponded to $12 \%$ of all, but their share was declining. Revenues per retained customer surpassed by $44 \%$ average revenues per customer. In the time period studied, the share of attrite customers was rapidly increasing, mainly to the detriment of customers with one purchase, because the share of retained customers remained relatively stabile. We can assume that attrition happens far more frequently with one-off customers. In June 2002, about two thirds of the customers' base were attrite (churn rate) and only $4 \%$ were retained (see Figure 5).

If we take into consideration the number of purchases made in the whole studied time period (and not only in the last six months), we can see that $80 \%$ of all customers made only one purchase. The McKinsey study similarly found out two thirds of customers made only one purchase (Agrawal et al., 2001).

Despite the fact that the value of an average purchase increased by $50 \%$ in the first half of 2002 and that estimated costs per transaction increased only by $19 \%$, Merkur's on-line shop did not break even. In 2002, revenues per transaction represented $72 \%$ of estimated costs per transaction.

\subsection{Conclusion}

In this paper, we continued our work in the field of business performance analysis in e-environment. We put forward a framework that tries to link different aspects of performance analysis and also to relate them to broader business environment on one side, and to the value of a company on the other side. The proposed framework can be applied in companies in a similar manner as some other models intended for business analysis. We suggested only a few measures that could be appropriate for analyzing e-business performance, but it is clear that every company needs to be treated individually. Also, if we want to increase the information value of measures/indicators, we need to compare actual results against the planned, track measures/indicators periodically or compare them to other companies in the same or related industries. In the case of Merkur's on-line shop, we could analyze only some of the suggested fields of business performance analysis. 
Figure 5: Customer retention and attrition ${ }^{11}$

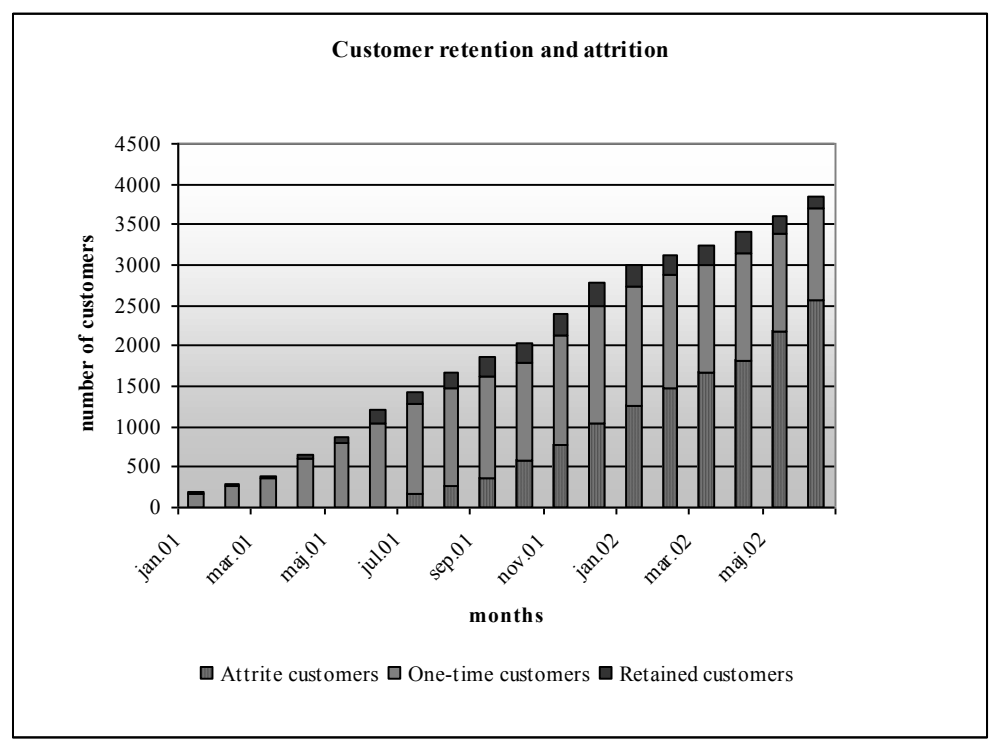

Source: Marc, 2003.

The framework could be used as a starting point for empirical research. For example, it would be useful to examine closely each of the parts of framework and find measures/indicators that are the most indicative. Such analysis would have to consider various e-business models and seek to identify the most representative measures or differences between business models. Furthermore, we should try to investigate the numerous relationships among different parts of the framework and verify the assumed links. Again, it would be possible to do that considering different business models and searching for similarities or differences among them. Finally, it would be interesting to carry out an international comparison and thereby find out the influences of e-environment on other parts of the framework.

\section{References}

1. $\quad$ Adams et al. (2000 - 2001). Managing with Measures, Measuring eBusiness Performance. Accenture.

2. Agrawal et al. (2001). E-performance: The Path To Rational Exuberance. The McKinsey Quarterly, Number 1. McKinsey \& Company.

3. Cisco Corporation (2001). Internet Corporation: Internet Value Matrix. URL: [http://www.cisco.com/ warp/public/750/icorporation/matrix.html], retrieved from Internet 12.02.2001

4. Donath (1999). The Quest for eBusiness Frameworks, Measuring and Tracking eBusiness Strategies. EBusiness Workshop White paper. The Pennsylvania State University, eBusiness Research Center (eBRC).

5. Lev and Demers (2000). A Rude Awakening: Internet Shakeout in 2000. Financial Research and Policy Working paper No. FR 00-13. Rochester: University of Rochester, William E. Simon Graduate School of Business Administration, The Bradley Policy Research Center.

6. Marc (2003). Analiziranje poslovanja v pogojih elektronskega poslovanja (in Slovenian: Analyzing Business Performance in e-Environment). Master thesis. Ljubljana: University of Ljubljana.

7. Mauboussin, Hiller (1999). CashFlow.com, Cash Economics in the New Economy. Frontiers of Finance, Equity Research, vol. 9. New York: Credit Suisse First Boston Corporation.

8. McLean (1995). The Canadian Performance Reporting Initiative, Performance Measures in the New Economy. URL: [http://cpri.matrixlinks.ca/Archive/PMNE/PerfMeasNE.html].

\footnotetext{
${ }^{11}$ Note: customers numbers have been transformed to keep them confidential.
} 
9. Melymuka (2001). Measuring your online profitability. The Australian Industry Standard, The Newsmagazine of the Internet Economy, 7. September. URL: [http://www.thestandard.com.au/articles/ display/0,1449,15120,00.html].

10. Merkur (2001). Vedenje porabnikov v spletni trgovini (in Slovenian: Consumer Behaviour in the On-line Shop). Merkur.

11. Nunes (2000). Creating a Unique Internet Business. Harpin Stephen (ed.): Kick-starter.com. London: Macmillan Press Ltd., $20-48$.

12. RIS 2000/2001 (2001). e-nakupovanje končnih potrošnikov (in Slovenian, engl.: RIS 2000/2001: eshopping by end consumers). Ljubljana: University of Ljubljana, Faculty of Social Sciences, Center for methodology and informatics, Project RIS.

13. RIS (2003). URL: [http://ris.org.si].

14. Sawhney (2001). TechVenture, New Rules on Value and Profit from Silicon Valley. New York: John Wiley $\&$ Sons Inc.

15. Stern Stewart \& Co., Razorfish Inc. (2001). Digital Value Added. URL: [http://www.sternstewart/ dva], retrieved from Internet in February 2001

16. Tekavčič, Marc (2003). E-Business In Central And Eastern European Countries: Measures For Business Performance Analysis. Journal of

17. Upton (2001). Business and Financial Reporting, Challenges From the new Economy. Financial Accounting Standards Board, April, 2001.

18. Vehovar (2000). Je slovenski trg za Internet premajhen? (in Slovenian, engl.: Is The Slovenian Market Too Small For Internet?). Ljubljana: University of Ljubljana, Faculty of Social Sciences, Center for methodology and informatics, Project RIS. 5

Notes 
Notes 